\title{
Photochromism of the Synthetic 4',7-Dihydroxyflavylium Chloride
}

\author{
Paulo Figueiredo, ${ }^{\dagger}$ João C. Lima, ${ }^{\ddagger}$ Helena Santos, ${ }^{\ddagger}$ Marie-Claude Wigand, $\$$ \\ Raymond Brouillard, 8 António L. Maçanita, ${ }^{\ddagger}$ and Fernando Pina ${ }^{*},+\neq$
}

Contribution from the Departamento de Quimica da Faculdade de Ciências e Tecnologia da Universidade Nova de Lisboa, Quinta da Torre, 2825-Monte de Caparica, Portugal, Instituto de Tecnologia Quimica e Biológica, Oeiras, Portugal, and the Laboratoire de Chimie des Polyphénols, associé au CNRS, Institut de Chimie, Université Louis Pasteur, Strasbourg, France

Received September 27, $1993^{\circ}$

\begin{abstract}
The synthetic compound 4',7-dihydroxyflavylium chloride shows an interesting photochromic effect at moderately acidic $\mathrm{pH}$ values. Pale yellow solutions of this compound, equilibrated in the dark at $\mathrm{pH} 3.4$, become bright yellow upon irradiation with $313-\mathrm{nm}$ light. Switching off the light, gives back the initial pale yellow solution. Photochemical methods, ${ }^{1} \mathrm{H}$ NMR, and molecular orbital calculations were used to elucidate this photochromic behavior. In solutions equilibrated in the dark $(\mathrm{pH}<5.7)$, the existence of two main species in equilibrium is demonstrated: the colored flavylium cation and the colorless trans-chalcone. Freshly prepared solutions of this compound at $\mathrm{pH} 6.2$ reveal the existence of another colored form, the quinonoidal base, which reacts thermally to yield trans-chalcone. An analogous reaction takes place in freshly prepared solutions at $\mathrm{pH}$ 3.4: the flavylium cation is partially converted into trans-chalcone. The extent of such conversion is $\mathrm{pH}$ dependent and nearly complete at $\mathrm{pH} 6.2$. Irradiation of transchalcone at the wavelength of $313 \mathrm{~nm}$ partially gives back the initial colored form, with concomitant formation of small amounts of photodegradation products. The turnover of the photochromic reaction is greater at $\mathrm{pH} 3.4$ than at $\mathrm{pH}$ 6.2. The photochromism is explained on the basis of a trans-cis photoisomerization. In fact the relative stability of the two chalcone isomers is reversed in the excited state, as predicted from molecular orbital calculations.
\end{abstract}

\section{Introduction}

The most significant molecules with a flavylium structure, the anthocyanins, are very important plant pigments, conferring to many flowers and fruits their diverse colors. ${ }^{\prime}$ In spite of the interest in natural or synthetic compounds of this family, ${ }^{2}$ namely as food additives, less attention has been lent to their photochemical properties.

Natural or synthetic flavylium salts in slightly acidic aqueous solutions undergo structural transformations which result in the formation of quinonoidal bases, hemiacetal, and chalcone forms, as depicted in Scheme $1 .^{3}$

Recently we studied at length the fluorescence spectra and decays $^{4}$ of the natural anthocyanin malvin (3,5-diglucosylmalvidin) as well as its photodegradation.5,6 Moreover, the multiple equilibria of malvin in moderately acidic aqueous solutions were elucidated by one- and two-dimensional ${ }^{1} \mathrm{H}_{\mathrm{NMR}}{ }^{7}$ Using this technique, apart from the flavylium cation, two hemiacetal forms and both cis and trans forms of chalcone were firmly characterized.

The present work extends these studies to the synthetic compound 4',7-dihydroxyflavylium chloride (Chart 1 ). Unlike natural anthocyanins and its aglycons, this synthetic salt exhibits an intense photochromic effect, which was characterized using the supra mentioned techniques.

t Universidade Nova de Lisboa.

\Instituto de Tecnologia Química e Biológica.

- Université Louis Pasteur.

- Abstract published in Advance ACS Abstracts, January 1, 1994.

(1) Harborne, J. B.; Grayer, R. J. In The Flavonoids, Advances in Research Since 1980; Harborne, J. B., Ed.; Chapman and Hall: London, 1988; pp 1-20.

(2) Brouillard, R. In The Flavonoids, Advances in Research Since 1980; Harborne, J. B., Eds.; Chapman and Hall: London, 1988; pp 525-538.

(3) Brouillard, R.; Iacobucci, G. A.; Sweeny, J. G. J. Am. Chem. Soc. 1992, 104, 7585-7560.

(4) Figueiredo, P.; Pina, F.; Vilas-Boas, L.; Maçanita, A. L. J. Photochem. Photobiol. $A$ 1990, 52, 411-424.

(5) Furtado, P.; Figueiredo, P.; Neves, H. C.; Pina, P. J. Photochem. Photobiol. A 1993, 75, 113-118.

(6) Figueiredo, P.; Pina, F.; Lima, J. C.; Maçanita, A. L.; Silva, M. G.; Neves, H.C. Fourth Winter Conference of the I-APS; Clearwater Beach, FL, 1992.

(7) Santos, H.; Turner, D. L.; Lima, J.C.; Figueiredo, P.; Pina, F.; Maçanita, A. L. Phytochemistry 1993, 33, 1227-1232.

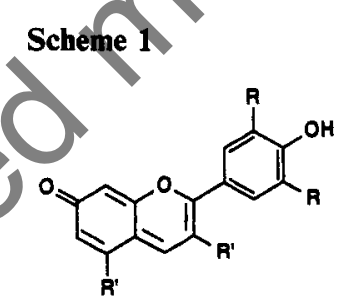

A. - Quinonoidal Base<smiles>[R]C1=CC(=C2Oc3cc(O)cc([R])c3C=C2[R])C=C([R])C1=O</smiles>

$A_{+}$- Quinonoidal Base<smiles>[CH+]C1C=CC=C1</smiles><smiles>C=[CH2+]</smiles><smiles></smiles><smiles>C=C=CC(=O)O</smiles>

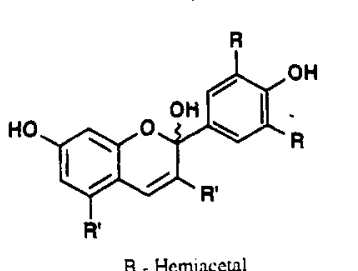<smiles>[R]/C(=C/c1c([R])cc(O)cc1O)C(=O)c1cc([R])c(O)c([R])c1</smiles>

B - Hemiacetal<smiles>[Z7]/C(=C\c1c([R])cc(O)cc1O)C(=O)c1cc([R])c(O)c([R])c1</smiles>

$R^{\prime}=\mathrm{H}, O H, O G l$
$R=H, O H . O H_{3}$,
$G l=$ Glucose

C, - rrans-Chalcune 
Chart 1<smiles></smiles>

4,7-dihydroxyflavylium cation

\section{Experimental Section}

Materials. The synthetic flavylium salt was prepared according to a published procedure. ${ }^{8}$ All other chemicals used were of analytical grade.

pH Measurements. The $\mathrm{pH}$ was measured with a Metrohm $713 \mathrm{pH}$ meter. The $\mathrm{pH}$ of the solutions was adjusted by addition of $\mathrm{HCl}(\mathrm{pH}$ $<2$ ) or buffer solutions for higher $\mathrm{pH}$ values, except for NMR experiments where a different procedure was used (see below).

Absorption Spectroscopy. Spectra were recorded on a Perkin-Elmer $\lambda 6$ spectrophotometer. A constant temperature of $20^{\circ} \mathrm{C}$ in the quartz cell $(d=1 \mathrm{~cm})$ was obtained by use of a Haake water-thermostated bath.

Molecular Orbital Calculations. Calculations were performed in a MicroVax 3100 computer, using the AM1 method. ${ }^{9}$

Photochemical Experiments. Light excitation was carried out using a medium pressure $\mathrm{Hg}$ lamp; the irradiation wavelengths were isolated with interference filters (Oriel). The incident light intensity was measured by ferric oxalate actinometry. ${ }^{10}$ Estimated errors for quantum yields are 10\%. Semipreparative irradiation for HPLC injection was performed in a 100-mL photochemical reactor from Applied Photophysics, equipped with a medium-pressure $\mathrm{Hg}$ lamp.

HPLC Apparatus. The HPLC equipment consisted of a L-6200 A Merck-Hitachi intelligent pump, with a Rheodyne 7125 injection valve, fixed volume loop of $20 \mu \mathrm{L}$. The effluent was monitored by means of a diode array UV-visible detector Merck-Hitachi L-4500. Quantitative measurements were made with a Merck-Hitachi D-6000 interface connected to a computing integrator.

The chromatographic assays were performed with a LiChrospher 100 RP-8 column (E. Merck, Darmstadt), particle size $5 \mathrm{~mm}, 250 \mathrm{~mm} \times 4.6$ $\mathrm{mm}$ i.d. The mobile phase was constituted by $A$ (aqueous solution of $\mathrm{HClO}_{4} \mathrm{pH}=1.5$ ) and $\mathrm{B}$ (methanol) in a gradient mode: 2 min at $\mathrm{B} \%$ $=2$, in $10 \mathrm{~min} B \%=20,15 \mathrm{~min}$ at $\mathrm{B} \%=20$, in $60 \mathrm{~min} \mathrm{~B} \%=60,8 \mathrm{~min}$ at $\mathrm{B} \%=60$, in $10 \mathrm{~min} B \%=2$, and $5 \mathrm{~min}$ at $\mathrm{B} \%=2$. The flow was 1.3 $\mathrm{mL} / \mathrm{min}$. A LiChrosphere RP-18, $4 \mathrm{~mm} \times 4 \mathrm{~mm}$, particle size $5 \mathrm{~mm}$ (E. Merck, Darmstadt) was used as a guard column.

Sample Preparation for NMR. 4',7-Dihydroxyflavylium chloride was dissolved in $\mathrm{DCl}$ (ca. $0.1 \mathrm{M}$ ) to a final concentration of $0.6 \mathrm{mM}$; the $\mathrm{pH}$ of the starting solution was typically 0.8 and, when required, was changed by addition of small aliquots of 1 or $0.1 \mathrm{M} \mathrm{NaOD} . \mathrm{pH}$ measurements were performed in the NMR tube using an Ingold glass electrode, and quoted $\mathrm{pH}$ values are direct meter readings without correction for the isotope effect ${ }^{11}$ and are denoted with an asterisk.

NMR Spectroscopy. One- and two-dimensional ${ }^{1} \mathrm{H}$ NMR spectra were obtained with either Bruker AMX-500 or AMX-300 spectrometers operating at 500.13 and $300.13 \mathrm{MHz}$, respectively. One-dimensional spectra were obtained with presaturation of the residual HDO resonance for $3 \mathrm{~s}$. The following conditions were used: $50^{\circ}$ flip angle, $7.3 \mathrm{~s}$ total recycle delay, and $64 \mathrm{~K}$ acquisition data points. Spectra were processed with 0.4 or $1 \mathrm{~Hz}$ line-broadening prior to Fourier transformation. Chemical shifts are referenced to the methyl resonance of ethanol (present in small amounts as contaminant) quoted at $1.2 \mathrm{ppm}$. Two-dimensional spectra were acquired over $10 \mathrm{ppm}$ bandwidth, collecting $2048\left(t_{2}\right) \times$ $512\left(t_{1}\right)$ data points. Spectra were recorded in the phase-sensitive mode by the time-proportional phase incrementation method and transformed to produce real matrices consisting of $1024 \times 1024$ data points. Nuclear Overhauser effect spectroscopy (NOESY) was performed according to

(8) Jurd, L. U.S. Patent 3266903,1966

(9) Quantum Chemistry Program Exchange; Department of Chemistry, Indiana University, USA.

(10) Hatchard, C. G.; Parker, C. A. Proc, R. Soc. London, Ser. A 1956 $235,518-536$.

(11) Glasoe, P. K.; Long, F. A. J. Chem. Phys. 1960, 64, 188-191.

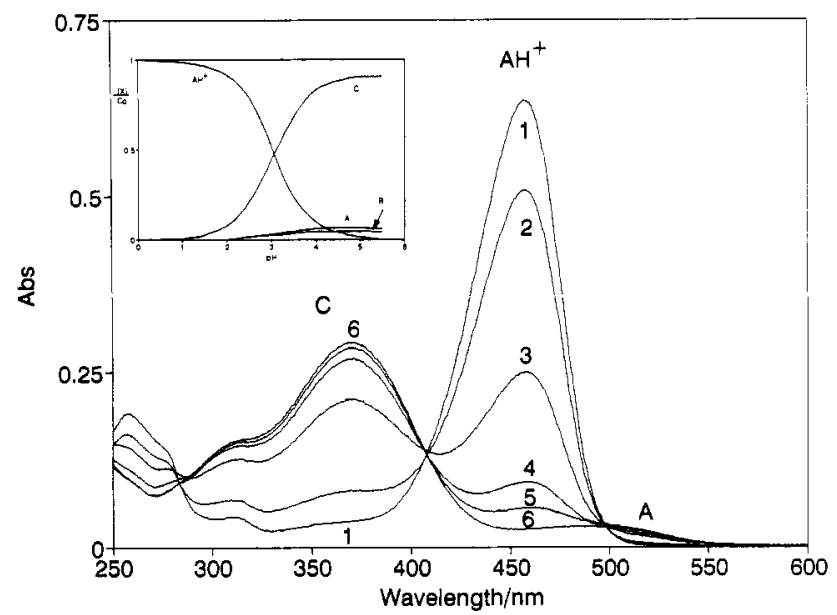

Figure 1. Absorption spectra of dark equilibrated aqueous solutions of 4,7-dihydroxyflavylium chloride $\left(2 \times 10^{-5} \mathrm{M}\right)$ as a function of $\mathrm{pH}$ : 1 , $\mathrm{pH} 1.0 ; 2, \mathrm{pH} 2.3 ; 3, \mathrm{pH} 3.2 ; 4, \mathrm{pH} 3.8 ; 5, \mathrm{pH} 4.3 ; 6, \mathrm{pH}$ 5.7. Inset: equilibrium distribution of the $\mathrm{AH}^{+}, \mathrm{B}, \mathrm{C}$, and $\mathrm{A}$ forms.

ref 12 , using mixing times of 0.5 or $1 \mathrm{~s}$. Correlation spectroscopy (COSY) was run according to the literature ${ }^{13,14}$

Results

Structural Transformation in the Ground State. (a) Equilibrated Solutions. Aqueous solutions of the synthetic flavylium salt $4^{\prime}, 7$ dihydroxyflavylium chloride, upon reaching the equilibrium in the dark, exhibit $\mathrm{pH}$ dependent absorption spectra (Figure 1), as previously reported. ${ }^{15,16}$ As the $\mathrm{pH}$ increases from 0 up to 5.7 , the characteristic flavylium cation $\left(\mathrm{AH}^{+}\right)$absorption band $(458$ nm) decreases, while the absorption of the chalcone (C) at 370 $\mathrm{nm}$ increases as well as a small absorption band at $495 \mathrm{~nm}$ attributed to the quinonoidal base (A). The inset of Figure 1 shows the equilibrium distribution as a function of $\mathrm{pH}$ for the following four species detected in solution: ${ }^{17}$ (i) the two main species, flavylium cation and chalcone, and (ii) the two minor species, quinonoidal base and hemiacetal (B).

${ }^{1} \mathrm{H}$ NMR spectroscopy allows the assignment of the resonances due to the flavylium cation. A spectrum was performed on a sample at $\mathrm{pH}^{*} \mathrm{ca} .0 .8$ where this is the only detectable form in solution (spectrum $\mathrm{A}$ in Figure 2). Resonances due to protons $2^{\prime}+6^{\prime}$ and $3^{\prime}+5^{\prime}$ at 8.37 and $7.16 \mathrm{ppm}$ (Chart 1 ) are immediately recognized from the expected relative intensity of two protons. Resonance due to proton 6 is identified from the displayed coupling pattern to proton $5(J=8.8 \mathrm{~Hz})$ and to proton $8(J=2.3 \mathrm{~Hz})$; the observation of a $2.3-\mathrm{Hz}$ splitting in the resonance at $7.53 \mathrm{ppm}$ allows its assignment to proton 8 . The full assignment of the spectrum was achieved by running COSY (Figure 3 ) and NOESY (not shown) spectra. In the NOESY spectrum there is a clear connectivity between the two proton doublet at $8.37 \mathrm{ppm}$ and the single-proton intensity doublet at 8.23 and this identifies these resonances to protons $2^{\prime}+6^{\prime}$ and 3 , respectively. All the remaining assignments follow directly from the clear connectivities observed in the COSY spectrum (Figure 3) and are shown in Table 1.

(b) Nonequilibrated Solutions. Aqueous solutions of 4',7dihydroxyflavylium chloride at $\mathrm{pH} 3.4$ (immediately upon dissolution in the dark) undergo spectral modifications (Figure

(12) Kumar, A.; Wagner, G.; Ernst, R. R.; Wüthrich, K. Biochem. Biophys. Res. Commun. 1980, 95, 1-6.

(13) Aue, W. P.; Bartholdi, E.; Ernst, R. R. J. Chem. Phys. 1976, 64, 2229-2246.

(14) Nagayama, K.; Kumar, A.; Wüthrich, K.; Ernst, R. R. J. Magn. Reson. 1980, 40, 321-334.

(15) Baranac, J. M.; Amič, D. S.; Spiridonovic, D. C.; GeorgijevicVukanovic, V. M. J. Serb. Chem. Soc. 1988, 53, 191-196.

(16) Amić, D.; Baranac, J.; Vukadinović, V. J. Agric. Food Chem. 1990, 38, 936-940.

(17) Brouillard, R. In Anthocyanins as Food Colors; Markakis, P., Ed.; Academic Press: New York, 1982; pp $1-40$ 
Table 1. Chemical Shifts $(\delta / \mathrm{ppm})$ and Scalar Couplings $(J / \mathrm{Hz})$ of the Three Forms of $4{ }^{\prime}, 7$-Dihydroxyflavylium Chloride by ${ }^{1} \mathrm{H}$ NMR in $\mathrm{D}_{2} \mathrm{O}$ at $27^{\circ} \mathrm{C}$

\begin{tabular}{|c|c|c|c|c|c|c|}
\hline & \multicolumn{2}{|c|}{ flavylium $^{a}$} & \multicolumn{2}{|c|}{ quinonoidal base ${ }^{b}$} & \multicolumn{2}{|c|}{ trans-chalcone ${ }^{b}$} \\
\hline & $\delta$ & $J$ & $\delta$ & $J$ & $\delta$ & $J$ \\
\hline $\mathrm{H}_{2}^{\prime}+\mathrm{H}_{6}^{\prime}$ & 8.37 & 8.9 & 8.13 & 8.9 & 7.99 & 8.8 \\
\hline $\mathrm{H}_{3}{ }^{\prime}+\mathrm{H}_{5}^{\prime}$ & 7.16 & 8.9 & 7.05 & 8.9 & 7.02 & 8.8 \\
\hline $\mathrm{H}_{3}$ & 8.23 & 8.8 & $7.76^{c}$ & 8.2 & 7.61 & 15.7 \\
\hline $\mathrm{H}_{4}$ & 9.03 & 8.8 & $8.42^{c}$ & 8.2 & 7.94 & 15.7 \\
\hline $\mathrm{H}_{5}$ & 8.13 & 8.8 & 7.57 & 8.2 & 7.62 & 8.8 \\
\hline \multirow[t]{2}{*}{$\mathrm{H}_{6}$} & 7.46 & 8.8 & 6.97 & 8.2 & 6.54 & 8.8 \\
\hline & & 2.3 & & 2.1 & & 2.3 \\
\hline $\mathbf{H}_{8}$ & 7.53 & 2.3 & 6.84 & 2.1 & 6.45 & 2.3 \\
\hline
\end{tabular}

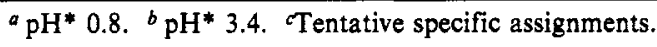

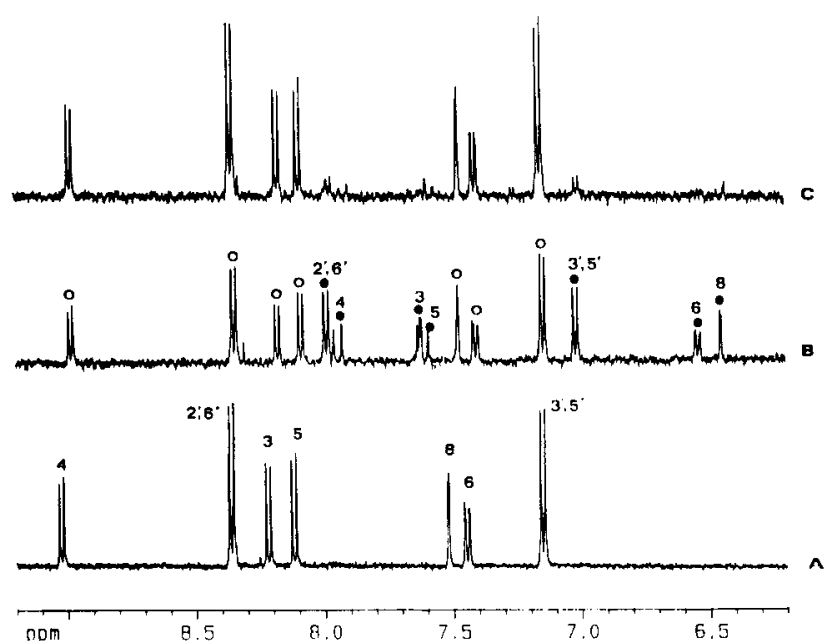

Figure 2. 500-MHz ${ }^{1} \mathrm{H}$ NMR spectra of $0.6 \mathrm{mM} 4^{\prime}, 7$-dihydroxyflavylium chloride in $\mathrm{D}_{2} \mathrm{O}$ at $27^{\circ} \mathrm{C}$ : (A) $\mathrm{pH}^{*} 0.8$, (B) same solution with $\mathrm{pH}^{*}$ adjusted to 3.4 , spectrum acquisition started $3 \mathrm{~h}$ after the $\mathrm{pH}$ change; and $(C)$ spectrum of the same sample of (B) acquired immediately after $30 \mathrm{~min}$ of illumination. Spectra were processed with $0.4 \mathrm{~Hz}$ line broadening prior to Fourier transformation. Resonances are indicated with the following symbols: $(0)$ flavylium cation and $(\bullet)$ trans-chalcone.

4a) which reflect predominantly the partial transformation of the flavylium cation into chalcone, until attaining the equilibrium concentration for this $\mathrm{pH}$ value, as depicted in the inset of Figure 1. An analogous experience carried out at pH 6.2 (Figure $4 \mathrm{~b}$ ) shows an initial spectrum due to the quinonoidal base absorption, which decreases to give a final absorption spectrum, characteristic of the chalcone form $\left(\lambda_{\max }=370 \mathrm{~nm}\right)$. A residual absorption of the quinonoidal base $\left(\lambda_{\max }=495 \mathrm{~nm}\right)$ reflects the partial conversion of $A$ into $C$, according to the results shown in the inset of Figure 1.

These results were firmly confirmed by proton NMR. When the $\mathrm{pH}^{*}$ of a sample containing flavylium cation is increased from 0.8 to 3.4 and spectra were run consecutively for approximately $3 \mathrm{~h}$, the intensities of the peaks due to the flavylium cation decrease with time, and new resonances increase concomitantly. The last spectrum of the series is shown in Figure 2 trace B. It is clear that, in addition to the flavylium cation, only one other form is present in solution. Assignment of the resonances due to this second form is also straightforward from NOESY and COSY spectra following strategy identical to that used for the assignment of the flavylium form; the corresponding chemical shifts are also shown in Table 1. The NOESY spectrum of a similar sample equilibrated at $\mathrm{pH}^{*} 3.4$ revealed connectivities between the resonances belonging to each form, but no cross peaks due to interspecies chemical exchange were detected, a result indicating that the rate of interconversion is very slow in the NMR time scale. The resonances of the new form present in Figure 2 spectrum B were assigned to trans-chalcone based on the following reasoning: the scalar coupling constant between protons 3 and 4 is $8.8 \mathrm{~Hz}$ in the flavylium form and has a similar

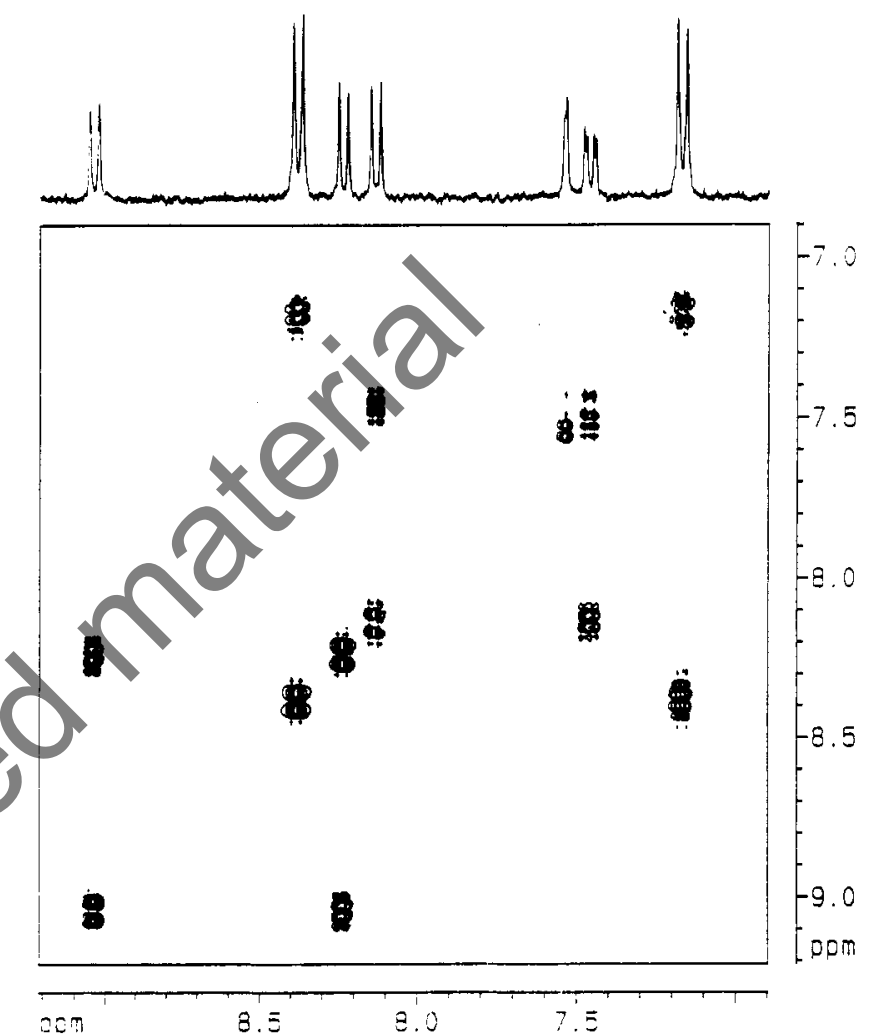

Figure 3. Phase-sensitive COSY spectrum ( $300 \mathrm{MHz}$ ) of a $0.6 \mathrm{mM}$ $4^{\prime}, 7$-dihydroxyflavylium chloride in $\mathrm{D}_{2} \mathrm{O}$ at $32^{\circ} \mathrm{C}$ and $\mathrm{pH}^{*} 0.8$. Before transformation, the data were multiplied by sinebell window functions in both dimensions.

value $(8.2 \mathrm{~Hz})$ in the quinonoidal base (see below) but increases to $15.7 \mathrm{~Hz}$ in this new form; since it is well established that for unsaturated systems ${ }^{3} J_{\text {trans }}$ is always higher than ${ }^{3} J_{c i s}$, it is concluded that there is a change in the configuration around the $\mathrm{C}_{3}-\mathrm{C}_{4}$ bond, going from cis to trans. Thus, NMR clearly shows that, upon increasing the $\mathrm{pH}^{*}$ to 3.4 , the flavylium form is converted in the dark into the trans-chalcone.

Photochemical Reactivity. Solutions of 4',7-dihydroxyflavylium chloride at $\mathrm{pH} \quad 1.0$ are stable upon standing for several months. Irradiation of these solutions with incident light of 313 $\mathrm{nm}$ results in the disappearance of the flavylium cation with a quantum yield of $1.5 \times 10^{-4}$. The photodegradation kinetics is followed by HPLC. The initial chromatogram shows a peak attributed to the flavylium cation (retention time $42 \mathrm{~min}$ ); this peak decreases with irradiation time, while three new peaks appear. Those peaks are identified as (i) 4-hydroxybenzoic acid (retention time $14 \mathrm{~min}$ ), (ii) 4-hydroxybenzaldehyde (retention time $15 \mathrm{~min}$ ), and (iii) 2,4-dihydroxybenzaldehyde (retention time $17 \mathrm{~min}$ ).

The photodegradation of $4^{\prime}, 7$-dihydroxyflavylium chloride shows a similar behavior to that observed for the aglycons of natural anthocyanins. ${ }^{5}$ The molecule is cleaved into two moieties, one with the structure of ring A, 2,4-dihydroxybenzaldehyde, 

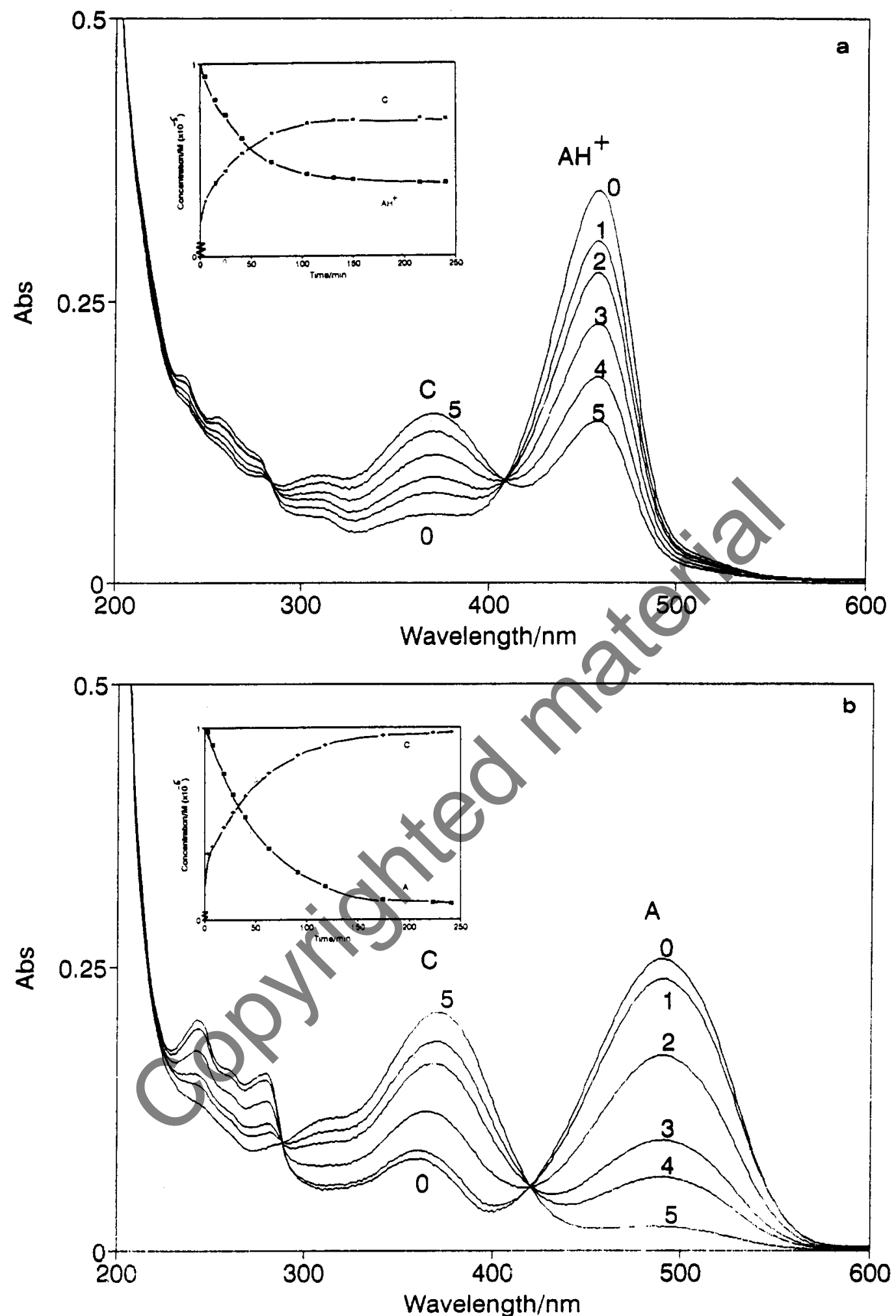

Figure 4. (a) Thermal evolution of $4^{\prime}, 7$-dihydroxyflavylium chloride $\left(10^{-5} \mathrm{M}, \mathrm{pH} 3.4, T=20^{\circ} \mathrm{C}\right) .0,5 \mathrm{~min}, 1,15 \mathrm{~min} ; 2,25 \mathrm{~min} ; 3,41 \mathrm{~min} ; 4,70$ $\mathrm{min}$; and 5, $240 \mathrm{~min}$. Inset: plot of the concentration vs time for the thermal reaction. (b) Thermal evolution of $4^{\prime}, 7$-dihydroxyflavylium chloride $\left(10^{-5} \mathrm{M}, \mathrm{pH} 6.2, T=20^{\circ} \mathrm{C}\right) .0,3 \mathrm{~min} ; 1,8 \mathrm{~min} ; 2,28 \mathrm{~min} ; 3,63 \mathrm{~min} ; 4,91 \mathrm{~min}$; and $5,241 \mathrm{~min}$. Inset: plot of the concentration vs time for the thermal reaction.

and the other with the structure of ring B, 4-hydroxybenzaldehyde, and its oxidation product 4-hydroxybenzoic acid.

At this $\mathrm{pH}$ value no postphotochemical dark reactions were observed.

Excitation at the irradiation wavelength of $436 \mathrm{~nm}$ (first singlet of the flavylium cation) gives no spectral modifications, as reported for natural anthocyanins. ${ }^{6}$

Photochromic Properties. Irradiation of preequilibrated so-

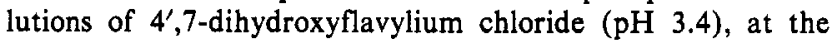

wavelength of $313 \mathrm{~nm}$, gives rise to an increase in the flavylium absorption (Figure 5a). The quantum yield for flavylium recovery, calculated on the basis of the light absorbed by the trans-chalcone, decreases with irradiation time, as depicted in the inset of Figure 5b. Extrapolation for the initial irradiation time allows to estimate a quantum yield of 0.1 for this reaction. The photochemical recovery of the colored flavylium cation form competes with the thermal conversion of flavylium into chalcone, which explains the decrease of quantum yield with time. The sequence of photo- 

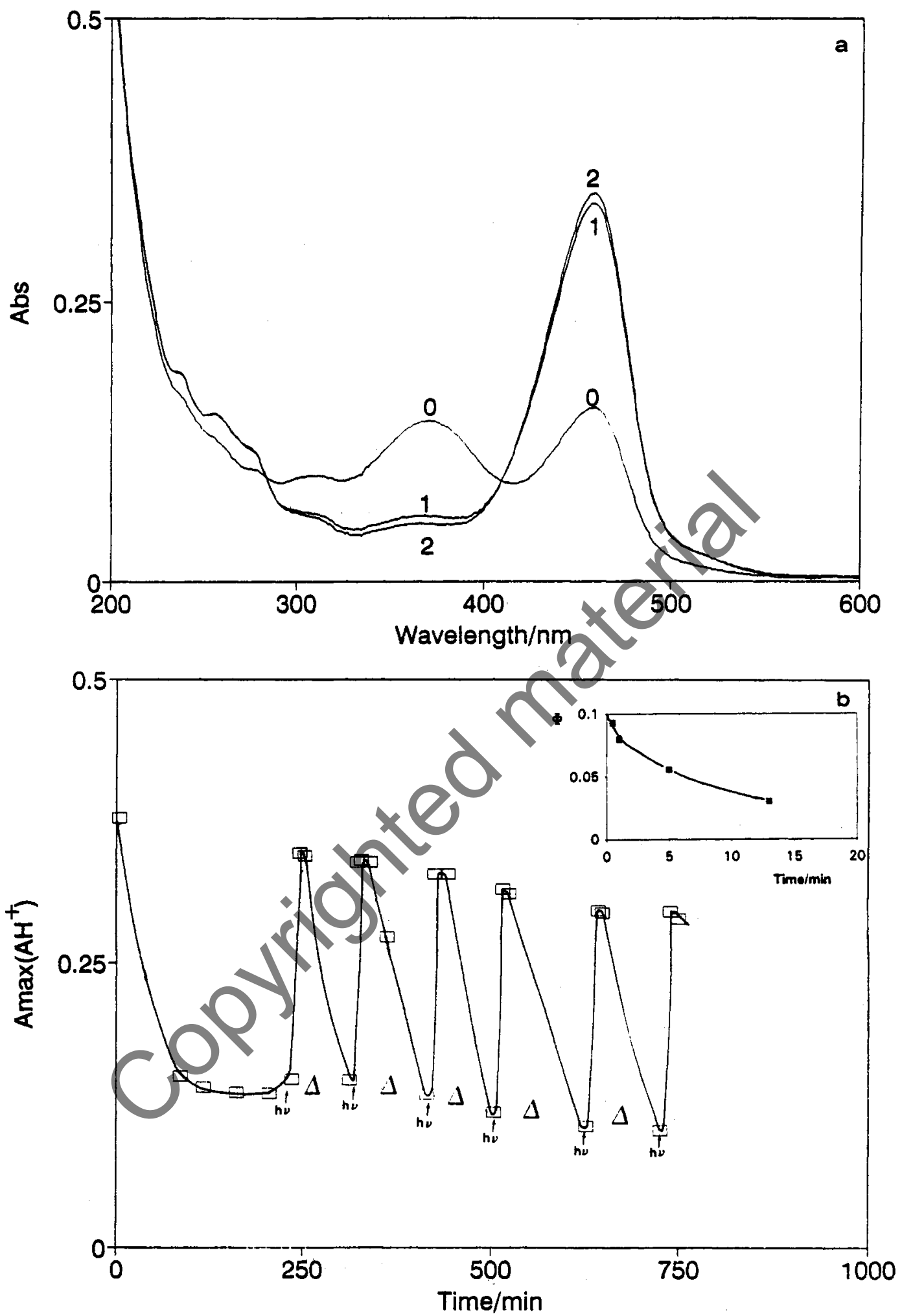

Figure 5. (a) Changes in the absorption spectra of 4,7-dihydroxyflavylium chloride $\left(10^{-5} \mathrm{M}, \mathrm{pH} 3.4, T=20^{\circ} \mathrm{C}\right)$ reflecting the effect of photoisomerization from $\mathrm{C}_{\text {trans }}$ to $\mathrm{C}_{c i s}$. Since $\mathrm{C}_{c i s}$ is in fast equilibrium with the hemiacetal form, which is also in fast equilibrium with the colored flavylium form, the result of the irradiation is an increase in the flavylium cation absorption (for details see text and Figure 2 , curve $C$ ). 0 , upon equilibration in the dark at $\mathrm{pH}=3.4 ; 1$, the same solution upon $8 \mathrm{~min}$ of irradiation; and 2, upon $16 \mathrm{~min}$ of irradiation. (b) Photochromic cycles consisting in the sequences of thermal equilibration followed by irradiation at $313 \mathrm{~nm}\left(10^{-5} \mathrm{M}, \mathrm{pH} 3.4, \lambda_{\mathrm{irt}}=313 \mathrm{~nm}, T=20^{\circ} \mathrm{C}\right)$.

chemical reaction, followed by thermal dark reaction, defines a photochromic system, whose efficiency is depicted in Figure 5b.

The same photochromic effect was detected for irradiation with light of $436 \mathrm{~nm}$, although the quantum yield of flavylium recovery is substantially lower $\left(10^{-3}\right)$. At the irradiation wavelength of $546 \mathrm{~nm}$ the quantum yield for the same reaction is smaller than $10^{-4}$.
The effect of irradiation at $313 \mathrm{~nm}$ was also monitored by NMR. Upon illumination of a solution thermally equilibrated in the dark, at $\mathrm{pH}^{*} 3.4$, the trans-chalcone (Figure 2, trace B) is converted into flavylium as demonstrated in spectrum $C$ of Figure 2. Once in the dark, slow transformation of flavylium back into trans-chalcone occurs, and again no additional form was detected by NMR under these experimental conditions. 
Table 2. Thermodynamic Constants for the $C_{c l s}$ and $C_{t r a n s}$ Isomers of 4',7-Dihydroxyflavylium Chloride Obtained by Modulation with the AM1 Method

\begin{tabular}{lcccccc}
\hline & $\mathrm{DH}_{\mathrm{f}}^{0} \mathrm{C}_{\text {cis }}\left(\mathrm{kcal} \cdot \mathrm{mol}^{-1}\right)$ & $\mathrm{DH}_{\mathrm{f}}^{0} \mathrm{C}_{\text {trans }}\left(\mathrm{kcal} \cdot \mathrm{mol}^{-1}\right)$ & $\mathrm{DH}_{\text {isom }}\left(\mathrm{kcal}^{-\mathrm{mol}}{ }^{-1}\right)$ & $K_{\text {isom }}$ & $\% \mathrm{C}_{\text {cis }}$ & $\% \mathrm{C}_{\text {trans }}$ \\
\hline ground state & -68.1 & -71.3 & -3.2 & 407 & 0.25 & 99.75 \\
excited state & 15.0 & 16.5 & 1.6 & 0.7 & 58 & 42 \\
\hline
\end{tabular}

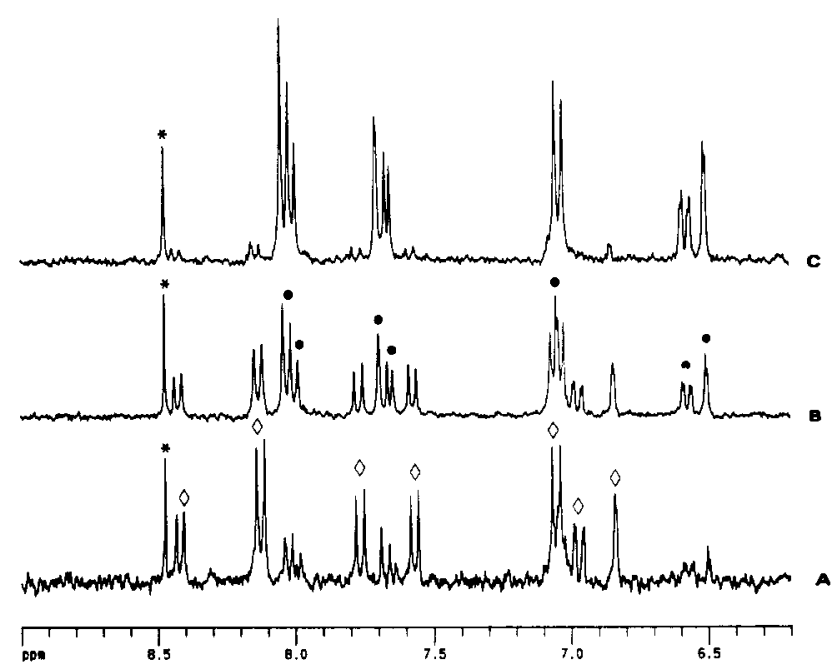

Figure 6. 300-MHz ${ }^{1} \mathrm{H}$ NMR spectra of 4',7-dihydroxyflavylium chloride in $\mathrm{D}_{2} \mathrm{O}$ at $32^{\circ} \mathrm{C}$. The compound was dissolved in approximately $0.1 \mathrm{M}$ $\mathrm{DCl}$, and the $\mathrm{pH}^{*}$ of this solution quickly increased to 5.9 with $1 \mathrm{M}$ $\mathrm{NaOD}$. Spectra were acquired at different times following this $\mathrm{pH}$ shock: (A) spectrum acquired for $9 \mathrm{~min}$ and starting immediately after the $\mathrm{pH}$ change, (B) acquisition started 17 min following $\mathrm{pH}$ shock, and (C) acquisition started at approximately $2.5 \mathrm{~h}$ following $\mathrm{pH}$ shock. Resonances due to the quinonoidal base are indicated with $\diamond$ and those due to trans-chalcone are labeled with $\bullet$; degradation product *.

At $\mathrm{pH} 6.2$ the photochromic system is once more operative. Irradiation of the thermally equilibrated solutions at $\mathrm{pH} 6.2$ with light of $313 \mathrm{~nm}$, produces a recovery of the quinonoidal base, with a quantum yield of the order of $10^{-3}$. The turnover of the cycle at this $\mathrm{pH}$ value is much smaller than at the former. Upon irradiation at the wavelength of $546 \mathrm{~nm}$ no recovery reaction was observed.

This different pattern is confirmed by NMR. When the $\mathrm{pH}^{*}$ of a sample of flavylium cation was rapidly increased from 0.8 to 5.9 (Figure 6), significant precipitation occurs, but the first spectrum run after the $\mathrm{pH}$ shock (spectrum $\mathrm{A}$ in Figure 6) is dominated by resonances assigned to the quinonoidal base (Table 1 ), which decrease with time to originate the resonances due to the trans-chalcone form (spectra $B$ and $C$ in Figure 6). Assignment of resonances due to the quinonoidal base is made by comparison with the firm assignments made for the other two forms.

\section{Discussion}

Molecular Orbital Calculations. In order to rationalize the above described photochromic effect, the formation enthalpies for the cis-and trans-chalcones in the ground and excited states were calculated using the AM1 method (Table 2). Assuming no significant changes in the solvation enthalpy for the two isomers, an approximate value for the cis-trans isomerization enthalpy was obtained, both for the ground and excited states (Table 2).

This result predicts a much more stable ground state for the trans isomer (more than $99 \%$ according to Table 2), in agreement with the NMR observation of only one chalcone isomer (trans) in contrast with the results for two natural anthocyanins [malvin? and oenin (3-glucosylmalvidin), Houbiers, C.; Santos, H. unpublished results] where both the trans and cis isomers coexist. For the excited state an inversion of the relative stability of the two isomers was calculated. On the other hand, using the experimental value of the cis-trans isomerization entropy obtained
Scheme 2

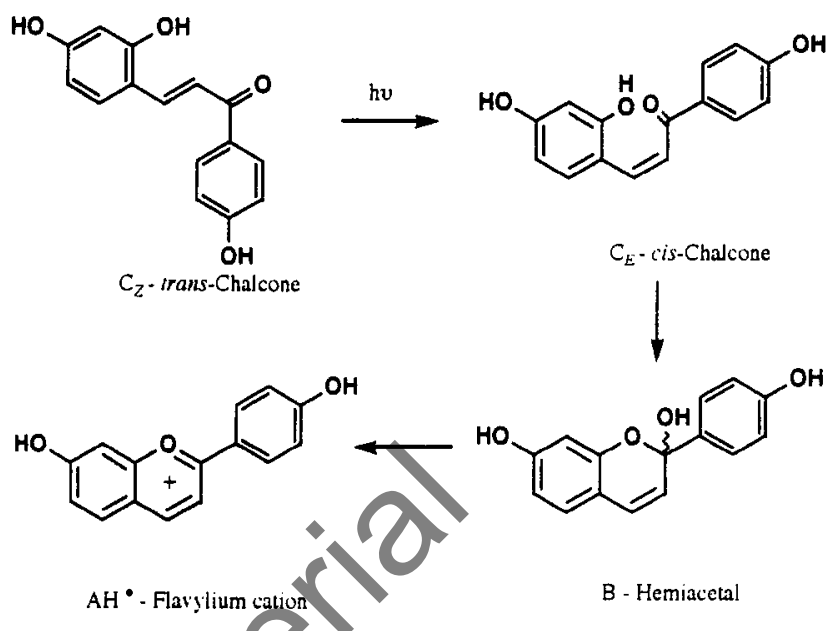

for malvin, ${ }^{7} 3.5 \mathrm{cal} \mathrm{mol}^{-1} \mathrm{~K}^{-1}$, an approximate value for the cistrans equilibrium constants in the ground and excited states can be calculated as well as the relative concentrations of the two isomers with respect to the total amount of chalcone (cis and trans), also shown in Table 2.

These data show an important change in the relative concentration of the chalcone isomers when the ground state and the first excited singlet state are compared, with the $c i s$ isomer existing in significant amounts only in the excited state.

The photochromic effect can thus be explained on the basis of a photoisomerization of trans- to cis-chalcone, which rapidly cyclizes to give the pyrylium ring structure characteristic of the flavylium cation. A simplified scheme showing the interference of light in the conversion of $\mathrm{C}_{\text {trons }}$ to $\mathrm{C}_{c i s}$ and then to $\mathrm{AH}^{+}$is given in Scheme 2. This reaction is reversed thermally in the dark, reaching an equilibrium, since the trans-chalcone, which is the only existing isomer on the ground state (Table 2) cannot undergo the direct ring closure reaction.

The turnover of this photochromic system (Figure 5b) is lowered by the existence of the photochemical degradation path above described for very acidic $\mathrm{pH}$ values, which is also operative at mildly acidic $\mathrm{pH}$ values.

The work here described constitutes a novel photochromic system based on trans-cis isomerization of a $\mathrm{C}=\mathrm{C}$ bond. Nature often employes this type of system. ${ }^{18}$ An important example is the isomerization of rhodopsin, the shift base of 11 -cis-retinal.

\section{Conclusions}

Three different forms of $4^{\prime}, 7$-dihydroxyflavylium in aqueous solution were detected and assigned by NMR spectroscopy: the flavylium cation, the trans-chalcone, and the quinonoidal base. The color enhancement observed upon illumination of moderately acidic solutions of the compound is due to a trans-to-cis photoisomerization followed by ring closure to give the colored flavylium cation. The color enhancement reaction is reversed in the dark, owing to a thermal reaction which converts back the flavylium cation into trans-chalcone.

Acknowledgment. Paulo Figueiredo and João Carlos Lima wish to express their gratitude to Junta Nacional de Investigação Científica e Tecnologica for grants, respectively, BD/1253/91IF and BD/840/90-IF.

(18) Saltiel, J.; Sun, Y.-P.; Photochromism Molecules and Systems; Dürr, H., Boas-Laurent, H., Eds.; Elsevier: Oxford, 1990; Chapter 3. 